\title{
Therapeutic Potential of Iridoid Derivatives: Patent Review
}

\author{
Hidayat Hussain ${ }^{1} *\left(\mathbb{D}\right.$, Ivan R. Green ${ }^{2}$, Muhammad Saleem ${ }^{3}$, Muhammad Liaquat Raza ${ }^{4}$ and \\ Mamona Nazir ${ }^{5}$ \\ 1 Leibniz Institute of Plant Biochemistry, Department of Bioorganic Chemistry, Weinberg 3, \\ D-06120 Halle (Salle), Germany \\ 2 Department of Chemistry and Polymer Science, University of Stellenbosch, Private Bag X1, Matieland, \\ Stellenbosch 7600, South Africa; irg@sun.ac.za \\ 3 Department of Chemistry, The Islamia University of Bahawalpur, Bahawalpur 63100, Pakistan; \\ drsaleem_kr@yahoo.com \\ 4 Department of Clinical Sciences, Biomedical Centre-BMC, Lund University Hospital, 22362 Lund, \\ Sweden; liaquathej@yahoo.com \\ 5 Department of Chemistry, Government Sadiq College Women University Bahawalpur, \\ Bahawalpur 63100, Pakistan; mamonanazir.de@gmail.com \\ * Correspondence: hussainchem3@gmail.com; Tel.: +49-152-26718166
}

Received: 31 March 2019; Accepted: 10 May 2019; Published: 16 May 2019

\begin{abstract}
Iridoids belong to a family of monoterpenoids comprising the cyclopentan[c]-pyran system; this class of compounds offers a wide range of biological effects, namely antileishmanial, anticancer, antiplasmodial, and anti-inflammatory potency. To date, a large number of biologically active iridoid derivatives have been reported from various plant families, including Rubiaceae, Plantaginaceae, Scrophulariaceae, and Verbenaceae. Furthermore, iridoids have the potential to form conjugates with other anticancer, antidiabetic, antileishmanial, and antimalarial drugs which synergistically have the potential to increase their effects. Additionally, future research should focus on the synthesis of halo analogs as well as preparing homo dimers or heterodimers of iridoids, since these might quite conceivably possess an increased bioactivity.
\end{abstract}

Keywords: iridoids; cytotoxic; antidiabetic; anti-inflammatory; antimalarial; trypanosomiasis

\section{Introduction}

Iridoids are an important class of monoterpenoids comprising the cyclopentan[c]-pyran system (Figure 1) [1,2]. Although initially isolated in the late nineteenth century, iridoids were only assigned their basic skeleton in 1958 by Halpern along with Schmid [3], namely plumieride (Figure 1), during their phytochemical investigation of Plumiera lancifolia (Apocynaceae). It is noteworthy that plumieride possesses some very interesting biological effects, including antibiotic and anticancer activity towards cancer cells and fungitoxicity [3,4]. Furthermore, the collective generic term "iridoid" was derived from the names iridolactone, iridomyrmecin, and iridodial compounds which were isolated from various plant species of the genus Iridomyrmex, since Iridomyrmex is one of the largest and most frequently encountered groups of ants, not plants [5]. Moreover, the iridoids and their glycosides can be further subdivided into carbocyclic iridoids and secoiridoids, the latter being obtained via oxidative cleavage of the 7,8-bond of the cyclopentane moiety [1,2]. Moreover, the majority of carbocyclic iridoids comprise a cis-fused cyclopentane ring having $\beta$-configured substituents at C-5 and C-9. On the other hand, very few trans-fused natural iridoids have been reported in the literature [2].

The tremendous chemodiversity in carbocyclic iridoids has been generated via modifications in the cyclopentane ring through insertion of hydroxyl, epoxy, keto, acyloxy, chloro, and olefin groups. 
Moreover, iridoids and their glycosides are found in many families of plants, such as Cornaceae, Rubiaceae, Garryaceae, Eucommiaceae, Garryaceae, Ericaceae, Buddlejaceae, Globulariaceae, Hippuridaceae, Orobanchaceae, Plantaginaceae, Scrophulariaceae, Verbenaceae, Bignoniaceae, Lentibulariaceae, Martyniaceae, Myoporaceae, Lamiaceae, Apocynaceae, Altingiaceae, Davidiaceae, Monotropaceae, Pyrolaceae, Stylidiaceae, and Globulariaceae [6]. Notably, iridoids possess antitumor (towards various cancer cell lines), neuroprotective, antioxidant, anti-inflammatory, antihepatotoxic, antiviral, anti-leishmanial, hypoglycaemic, antiallergic, hypolipidemic, antispasmodic, antimicrobial, cardiovascular, choleretic, immunomodulator, and molluscicidal effects $[7,8]$.

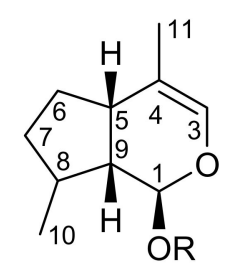

Carbocyclic

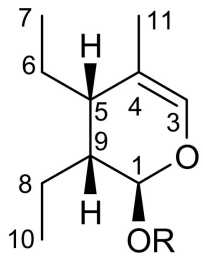

Secoirdoid

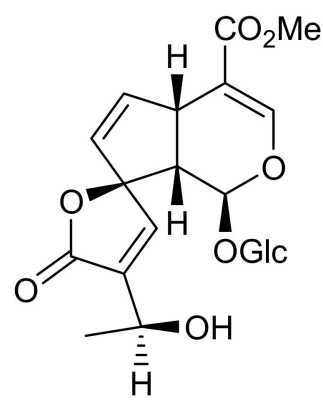

Plumieride

Figure 1. Basic skeletons of iridoids.

\section{Patents Filed for Iridoids}

Iridoids have over the past decades played a vital role in drug discovery as is abundantly apparent from the range of biological effects reported in published patents. It is noteworthy that most patents on iridoids describe their anticancer effects, which are briefly illustrated in Figure 2.

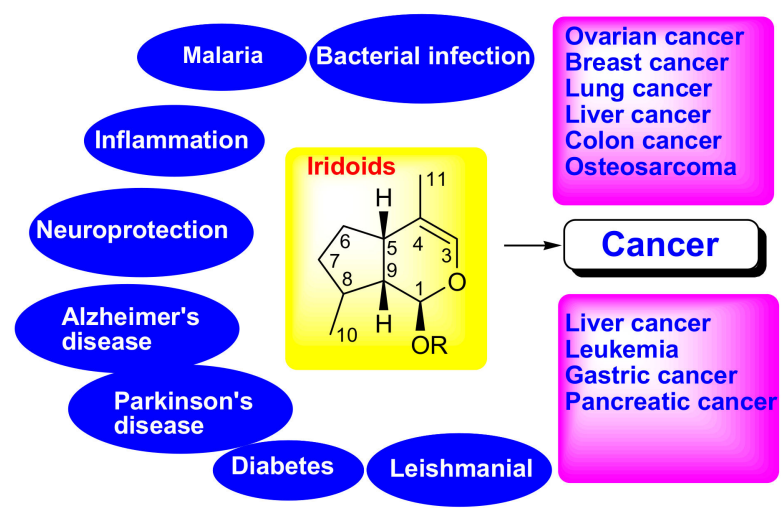

Figure 2. Therapeutic applications of iridoids.

\section{Iridoid Derivatives as Anticancer Agents}

Gardenia jasminoides Ellis. forms an integral part of a Chinese herbal medicine used to treat detoxification, red eyes, sore throat, fever, dark urine, jaundice, astringent pain, epistaxis bruises, cough, and canker sores [9]. Wu [9] published a patent and reported on the iridoid $\mathbf{1}$ (Figure 3) which was isolated from $G$. jasminoides and which displays an encouraging concentration-dependent in vitro anticancer effect towards the renal cancer cell line (RC-2). In another patent, a novel iridoid 2 isolated from Swertia mussotii Franch. was shown to display strong in vitro anticancer effects towards ovarian cancer (SKOV3). Further pharmacological investigations have demonstrated that the iridoid 2 blocks tumor cells at the $G_{0} / G_{1}$ stage via a combination with tyrosine kinase phosphorylation ATP of the EGFR/HER2 acceptor and this compound then suppresses its phosphorylation [10]. Yang et al. [11] published a patent on natural iridoids 3 and 4 isolated from the Valeriana species and tested them for their anticancer effects towards three cancer cells, two breast cancers (MDA-MB-231 and MCF-7) 
and one lung cancer (A549). It is noteworthy that both compounds possess almost the same level of anticancer potential towards the two breast cancers (MDA-MB-231: 3: $\mathrm{IC}_{50}: 13.4 \mu \mathrm{mol} / \mathrm{L} ; 4: \mathrm{IC}_{50}$ : $\left.13.8 \mu \mathrm{mol} / \mathrm{L} ; \mathrm{MCF}-7: 3: \mathrm{IC}_{50}: 12.8 \mu \mathrm{mol} / \mathrm{L} ; 4: \mathrm{IC}_{50}: 13.7 \mu \mathrm{mol} / \mathrm{L}\right)$. On the other hand, iridoid 3 was almost twice as active as 4 towards the lung cancer (A549: 3: $\mathrm{IC}_{50}: 13.8 \mu \mathrm{mol} / \mathrm{L} ; 4: \mathrm{IC}_{50}: 26.3 \mu \mathrm{mol} / \mathrm{L}$ ) which would suggest that increased acylation on the main nucleus decreases anti-lung cancer activity.<smiles>CC(C)CC(=O)OC1OC=C(C=O)[C@H]2C[C@H]3OC(C)(C)OC[C@H]3[C@H]12</smiles>

1<smiles>CC(=O)O[C@@H]1C=C[C@H]2C(COC(=O)CC(C)C)=CO[C@@H](OC(=O)CC(C)C)[C@H]12</smiles><smiles>CC(C)CC(=O)OCC1=CO[C@@H](OC(=O)CC(C)C)C[C@H]1COC(=O)CC(C)C</smiles>

2<smiles>CC(C)CC(=O)O[C@H]1OCC(C=O)=C2C=C[C@](O)(CO)[C@H]21</smiles><smiles>CCOC[C@@]1(O)C(COC(C)=O)=COC2=C[C@H](OC(=O)CC(C)C)[C@H](OC(=O)CC(C)C)C21</smiles>

3

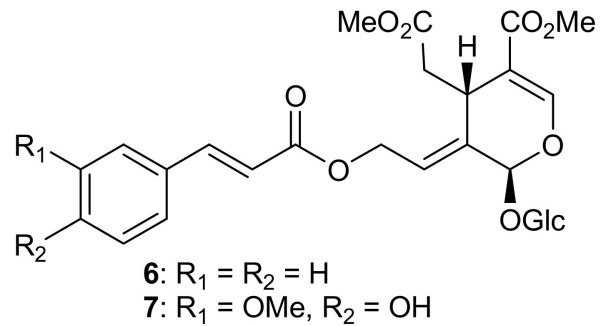

4<smiles>CC(=O)CC(C)C</smiles>

Figure 3. Structures of cytotoxic iridoids 1-9.

Valeriana jatamansii is also a medicinal herb used as an aphrodisiac, antiseptic, nerve tonic, tranquilizer, expectorant, antispasmodic, ophthalmic, febrifuge, and sedative. In addition, V. jatamansi is used as a tonic to treat hysteria, eurosis, scorpion stings, snakebites, asthma, and cholera [12]. Moreover, its roots are employed as a laxative, a carminative, and to treat burning sensation, blood diseases, skin disease, cholera, ulcers, and throat troubles. Furthermore, the root of $V$. jatamansi possesses adulticidal and larvicidal effects [12]. Yan et al. [13] published a patent in which they demonstrated that iridoid 5, isolated from $V$. jatamansi, displays very encouraging anticancer effects towards various cancer cells. Compound 5 demonstrates potent anticancer effects towards breast cancer $\left(\mathrm{MCF}-7: \mathrm{IC}_{50}=7.4 \mu \mathrm{g} / \mathrm{mL}\right)$, liver cancer $\left(\right.$ HepG-2: $\left.\mathrm{IC}_{50}=11.7 \mu \mathrm{g} / \mathrm{mL}\right)$, lung cancer $\left(\mathrm{A} 549: \mathrm{IC}_{50}=17.9 \mu \mathrm{g} / \mathrm{mL}\right)$, rectum/colon cancer $\left(\mathrm{HT}-29: \mathrm{IC}_{50}=3.1 \mu \mathrm{g} / \mathrm{mL}\right)$, osteosarcoma $\left(\mathrm{MG}-63: \mathrm{IC}_{50}\right.$ $=3.5 \mu \mathrm{g} / \mathrm{mL}$ ), and leukemia $\left(\mathrm{K} 562: \mathrm{IC}_{50}=12.7 \mu \mathrm{g} / \mathrm{mL}\right.$. In the same year, Yang et al. [14] in another patent reported on a further iridoid (structure not shown) isolated from $V$. jatamansii, and evaluated it for its anticancer activity towards various cancer cells. This iridoid displays potent anticancer effects towards two gastric cancer cell lines (SGC-7901: $\mathrm{IC}_{50}=5.94 \mu \mathrm{g} / \mathrm{mL} ; \mathrm{MKN}-45: \mathrm{IC}_{50}=1.39 \mu \mathrm{g} / \mathrm{mL}$ ), lung cancer $\left(\mathrm{NCI}-\mathrm{H} 1975: \mathrm{IC}_{50}=2.61 \mu \mathrm{g} / \mathrm{mL}\right)$, pancreatic cells $\left(\mathrm{BXPC}-3: \mathrm{IC}_{50}=1.71 \mu \mathrm{g} / \mathrm{mL}\right)$, and colon cancer (HT-29: $\left.\mathrm{IC}_{50}=4.43 \mu \mathrm{g} / \mathrm{mL}\right)$. 
Meng et al. [15] published a patent on the isolation of two iridoid glycosides 6 and 7 from Jasminum lanceolarium and demonstrated that they possess anticancer effects towards the lung cancer cell line A549 with $\mathrm{IC}_{50}$ values of 161.1 and $39.0 \mu \mathrm{M}$, respectively. In another patent Zhang et al. [16] reported the anticancer effects of two other natural iridoids, isovaleroxy-hydroxy-dihydrovaltrate (8) and valtrate $\mathrm{J}(9)$, where each compound was shown to display potent anticancer effects towards two ovarian cancer cells, namely A2780 (8: IC $50=2.6 \mu \mathrm{M}$; 9: IC $50=3.1 \mu \mathrm{M})$ and OVCAR-3 $\left(8: \mathrm{IC}_{50}=2.3 \mu \mathrm{M}\right.$; 9: $\left.\mathrm{IC}_{50}=2.8 \mu \mathrm{M}\right)$. However, the anticancer effects of compounds 8 and 9 towards ovarian epithelial cancer cells (IOSE-144: 8: $\mathrm{IC}_{50}=17.9 \mu \mathrm{M}$; 9: $\mathrm{IC}_{50}=21.6 \mu \mathrm{M}$ ) were found to be not as impressive as the activities towards OVCAR-3 and A2780.

Zhang et al. [17] reported in a patent that compounds 10-18 (Figure 4) possess cytotoxic effects against A549 (lung cancer), PC-3 (prostate cancer), HCT-8 (colon cancer), and BEL-7402 (liver cancer), with $\mathrm{IC}_{50}$ values ranging from 0.89 to $9.76 \mu \mathrm{g} / \mathrm{mL}$. Interestingly, iridoid 12 possesses potent cytotoxic effects towards HCT- 8 and PC-3 with $\mathrm{IC}_{50}$ values of 0.89 and $1.06 \mu \mathrm{g} / \mathrm{mL}$, respectively. In addition, compound 12 was also shown to be active towards BEL-7402 with an $\mathrm{IC}_{50}$ of $2.11 \mu \mathrm{g} / \mathrm{mL}$. Moreover, compound 17 has displayed significant effects towards four cancer cells with $\mathrm{IC}_{50}<4 \mu \mathrm{g} / \mathrm{mL}$, and in particular its activity towards HCT- 8 and BEL-7402 with $\mathrm{IC}_{50}$ values of 1.41 and $2.03 \mu \mathrm{g} / \mathrm{mL}$, respectively, are indeed noteworthy. However, compounds 15-17 possess good activities towards HCT-8 and BEL-7402, with $\mathrm{IC}_{50}<3 \mu \mathrm{g} / \mathrm{mL}$. In another patent Khanuja et al. [18] tested loganin (19) and its semi-synthetic analogs 20-24 towards MCF-7, PA-1 (ovary), WRL (liver), COLO-320, (colon) and Caco2 (colon). It has been reported that these compounds possess cytotoxic effects with $\mathrm{IC}_{50}$ values ranging from 0.04 to $4.85 \mu \mathrm{g} / \mathrm{mL}$. Compounds 21 and 23 were the two most potent iridoids in this series since they were observed to be active towards all four (aforementioned) cancer cells, with their $\mathrm{IC}_{50}$ values ranging from 0.04 to $0.85 \mu \mathrm{g} / \mathrm{mL}$ and 0.04 to $0.54 \mu \mathrm{g} / \mathrm{mL}$, respectively. It is noteworthy that compounds 21-24 were seen to be more active towards COLO-320 than the standard vinblastine, while compounds 21-23 possess better effects towards WRL than the standard vinblastine. Moreover, compound 23 was seven time more active towards $\mathrm{CaCo} 3$ than vinblastine. 


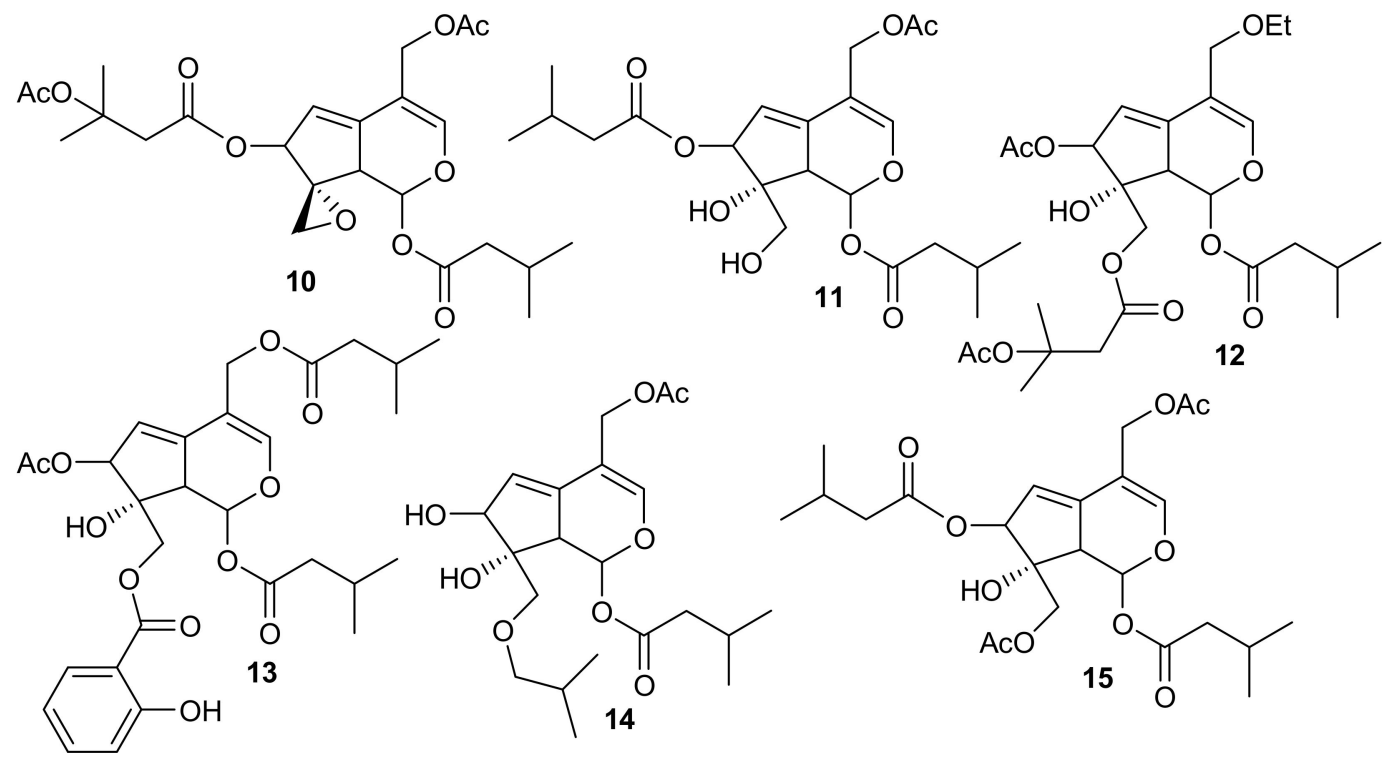<smiles>CC(C)CC(=O)OCC1=COC(OC(=O)CC(C)C)C2C1=CC(OC(=O)CC(C)C)[C@]2(O)CCl</smiles>

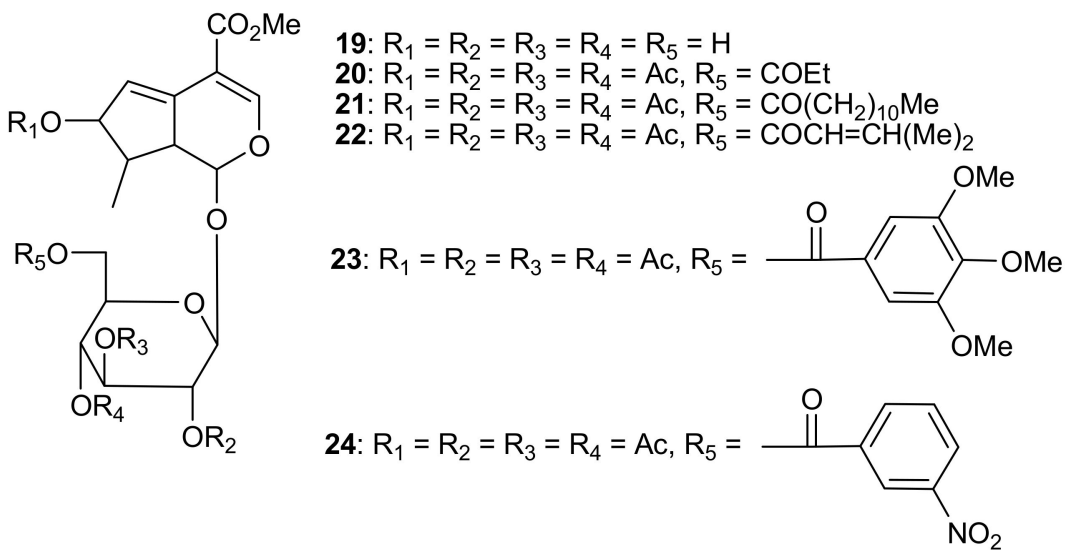

Figure 4. Structures of cytotoxic iridoids 10-24.

\section{Iridoid Derivatives as Anti-Trypanosomal Agents}

The trypanosomatid, together with Chagas disease, causes over 19,000 deaths and some 100,000 disabilities each year [19]. Yamaoka et al. [20] have reported that an extract of Morinda lucida leaves displays potent biological activities towards Trypanosoma brucei brucei. Purification of natural products contained in the active fractions of Morinda lucida has been observed to provide three tetracyclic iridoids 25-27 (Figure 5) with three 5-membered rings, one 6-member ring, and a spiro carbon. It is noteworthy that all three compounds possess strong anti-trypanosomal effects. Compounds $\mathbf{2 6}$ and $\mathbf{2 7}$ in particular inhibit the expression of ot-tubulin and flagella formation of trypanosoma cells. In addition, the latter two compounds (26 and 27) induce early and late stage apoptosis in trypanosoma cells. On the other hand, compound $\mathbf{2 5}$ is more active than $\mathbf{2 6}$ and the latter does not induce apoptosis in trypanosoma cells. Further study has demonstrated that compound $\mathbf{2 6}$ displays less cytotoxicity in mammalian cells than compound 25. However, the most valuable active therapeutic agent should have strong 
anti-trypanosomal effects coupled with low cytotoxicity in mammals [20]. Interestingly, iridoid 27 was the most active compound with an $\mathrm{IC}_{50}$ of $0.43 \mu \mathrm{M}$, followed by compound $\mathbf{2 6}\left(\mathrm{IC}_{50}=1.27 \mu \mathrm{M}\right)$ and $25\left(\mathrm{IC}_{50}=3.75 \mu \mathrm{M}\right)$. Further results showed that the $\mathrm{IC}_{50}$ values $(\mu \mathrm{M})$ of compound 26 towards various human cancer cells (colon cancer cells (Caco2, LoVo, HCT-15), stomach cancer cells (KATOIII), and leukemia (Jurkat, U937, HL-60, THP-1)) are almost between two and a hundred-fold higher than compound 25. Moreover, the $\mathrm{IC}_{50}$ values of compound $\mathbf{2 6}$ towards normal fibroblast (HF-19) and colon cancer cells (HCT-15) are $>50 \mu \mathrm{M}$, which clearly demonstrates that this compound is non-toxic at the highest dose for HCT-15 and HF-19. The $\mathrm{IC}_{50}$ values of compound 25 towards trypanosoma cells, however, is between 1 and $1.5 \mu \mathrm{M}$, while for compound 26 the $\mathrm{IC}_{50}$ values range between 3 and $5 \mu \mathrm{M}$. Moreover, the selectivity index (SI) of iridoid 25 is between 0.09 and 12.63, while that for iridoid 26 is between 3.2 and 13. Based on the $\mathrm{IC}_{50}$ and SI values, it may thus be concluded that compound 26 displays lower cytotoxicity in human cells and possesses high anti-trypanosomal effects. Moreover, the SI of compound 25 is $<1.00$ in a number of cell lines (KATOIII: 0.09; LoVo: 0.09). On the other hand, compound 26 has SI values higher than compound 25 in all the tested cell lines. It is interesting to note that the anti-trypanosomal effect of iridoid $\mathbf{2 7}$ was observed to be higher than both iridoids 25 and 26. Furthermore, compound 27 possesses a lower cytotoxicity in human cells and its activity towards trypanosoma cells is $<1$, while its SI has been seen to be between 11 and 42 [20]. In order to determine the mechanism of the anti-trypanosomal effects of compounds 25-27, results were obtained regarding compound 26-treated Trypanosoma cells when subjected to a Nexin assay which showed that compound 26 induced strong apoptosis in the early $(7.8 \%)$ and late stages $(4.4 \%)$ of apoptotic cells. Furthermore, cell cycle analysis has demonstrated a significant reduction in cell numbers in the M and G2 phase of the compound $\mathbf{2 6}$ cell cycle. Additionally, an indication of DNA fragmentation was evident from the detection of large numbers of cells with low DNA content during compound $\mathbf{2 6}$ apoptosis. However, no induction of apoptosis was observed for compound 25. In addition, compound $\mathbf{2 6}$ was administered both intraperitoneally and intravenously for six days at a dose of $50 \mathrm{mg} / \mathrm{kg}$ body weight for female $\mathrm{Balb} / \mathrm{C}$ mice when treated with compound $\mathbf{2 6}$. Interestingly, compound $\mathbf{2 6}$ has been observed to cause a potent reduction in parasitemia. Based on these in vivo studies, it has been concluded that compound 26 possesses good anti-trypanosomal effects in mice.

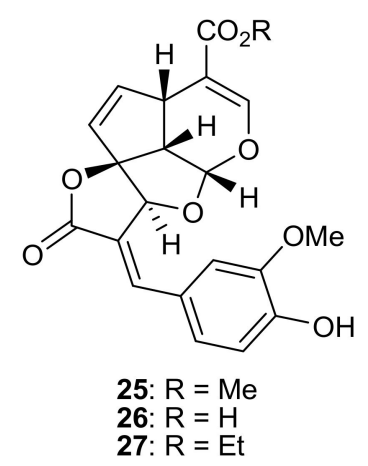

Figure 5. Structures of iridoids 25-27.

\section{Iridoid Derivatives as Antileishmanial Agents}

Leishmaniasis is common in about 88 countries around the world and is a disease that affects around 12 million people. It has been found that $>90 \%$ of visceral Leishmaniasis (VL) patients are found in Bangladesh, India, Sudan, and Brazil, and about 500,000 cases of VL are reported annually. Various drugs used to treat leishmaniasis unfortunately have side effects and resistance has developed over the years towards these drugs [21]. As a potential substitute, iridoids offer their candidature to be considered as a new drug therapy. The three iridoids 25-27, isolated from Morinda lucida, have been evaluated for their antileishmanial activity towards L. hertigi and Ghanaian field strain 010 [20]. The results of this evaluation demonstrated that compounds 25 and $\mathbf{2 6}$ possess similar and significant in vitro antileishmanial activity towards L. hertigi with MIC values of $2.87 \mu \mathrm{M}$. On the other hand, 
compound 27 displayed almost twice the activity towards Ghanaian field strain 010 than compound 25 (27: $2.60 \mu \mathrm{M} ; 25: 4.17 \mu \mathrm{M}$ ). The aforementioned results have demonstrated that the alkyl substituents of the carboxylic acid ester moiety play an important role in activity towards the 010 strain, but not against $L$. hertigi, since compounds 25 and 27 are methyl and ethyl esters, respectively.

Moreover, compound 26, being the free acid, has not been observed to show any antileishmanial effects towards both L. hertigi and Ghanaian field strain 010. In addition, FACS analysis has demonstrated that compounds 25 and 27 possess fair activities with $\mathrm{IC}_{50}$ values of 4.24 and $3.38 \mu \mathrm{M}$, respectively. Moreover, compound $\mathbf{2 5}$ is a stereoisomer of oruwacin isolated from M. lucida which has been shown to possess antileishmanial effects. Interestingly, oruwacin and compound $\mathbf{2 5}$ are enantiomers with optical rotations of -188.5 and +193 respectively. In addition, it has been reported that compound 25 has antileishmanial, anti-trypanosomal, and anti-plasmodial properties, while oruwacin only possesses antileishmanial properties. Furthermore, two other isomeric tetracyclic iridoids, plumericin $\left(\mathrm{IC}_{50}=0.21 \mu \mathrm{g} / \mathrm{mL}\right)$ and isoplumericin $\left(\mathrm{IC}_{50}=0.28 \mu \mathrm{g} / \mathrm{mL}\right)$, have been observed to possess excellent antileishmanial effects in the non-patent literature regarding L. amazonensis [20].

\section{Iridoid Derivatives as Antiplasmodial Agents}

Malaria remains a major health problem in many areas of the world. It is estimated that $50 \%$ of the world's population are at risk of contracting this deadly infection. In 2015 the WHO reported 214 million clinical cases along with 438,000 deaths [22]. It has furthermore been reported that 109 countries were endemic for malaria in 2008, and of these, 45 countries are within the WHO African region [23]. Malaria additionally affects the whole region in which it occurs by decreasing the productive population, which in turn results in an annual 1.3\% average loss of economic growth [2]. It is alarming that approximately 3.3 billion people all over the world are at risk of being infected and developing symptoms of malaria while 1.2 billion are at high risk, which translates into a 1 in 1000 chance of people contracting malaria in a year [3]. Unfortunately for Africa, which is already burdened by so many economic constraints, the additional annual economic burden as a consequence of the disease has been estimated to be around 12 billion US\$ in direct costs. This leads to a reduced GDP growth of $1.3 \%$ [24].

It is common knowledge that malaria is caused by the protozoan parasite of the genus Plasmodium, while P. vivax, P. malariae, P. ovale, and P. falciparum are the major species that cause infection in humans. Furthermore, of these Plasmodiam species, P. falciparum is the most dangerous and causative agent, accounting for roughly half of all clinical cases of malaria [25]. The three iridoids 25-27 (Figure 5) have been evaluated for their antiplasmodial activity towards P. falciparum (3D7 strain). This study revealed that compound 25 possesses a significant antiplasmodial effect with an $\mathrm{IC}_{50}$ value of $<1 \mu \mathrm{M}$ $(0.14 \mu \mathrm{M})$. In addition, compound 26 also displays a significant antiplasmodial activity with an $\mathrm{IC}_{50}$ value of $1.22 \mu \mathrm{M}$. On the other hand, iridoid 27 was observed to be only moderately active with an $\mathrm{IC}_{50}$ value of $10.3 \mu \mathrm{M}$. Further toxicological screening using various mammalian cells, namely normal skin fibroblasts, has demonstrated that compounds 25 and 26 possess SI values $>40$, while iridoid 27 has SI values ranging between 0.46 and 1.76 [20].

\section{Iridoid Derivatives as Anti-Inflammatory Agents}

Quite recently, Liu et al. [26] have reported that 7-O-ethyl-morroniside (28) (Figure 6) displays potent in vitro and in vivo anti-inflammatory activity and that this iridoid can be used to treat various inflammatory diseases. In a patent study, Li et al. [27] demonstrated that the iridoid glycoside with the general formula 29 potently suppresses the effect of nuclear factor-kappa B (NF- $\mathrm{B})$, and thus the mRNA level. In addition, this compound has been shown to significantly reduce the expression of relevant inflammatory factors. In another patent, the two iridoids $\mathbf{3 0}$ and 31, isolated from Gentiana triflora Pall., were described as displaying significant anti-inflammatory effects [28]. Barleria cristata Linn. (Acanthaceae) is employed traditionally to treat inflammatory disorders, toothache, anemia, fever, bronchitis, pains, swelling, blood diseases, coughing, and asthma [29,30]. Karan et al. [28] 
isolated three iridoids, i.e., barlerin (32), acetyl barlerin (33), and shanzhiside methyl ester (34), from B. cristata, and found that the three metabolites possess potent anti-inflammatory effects.<smiles></smiles>

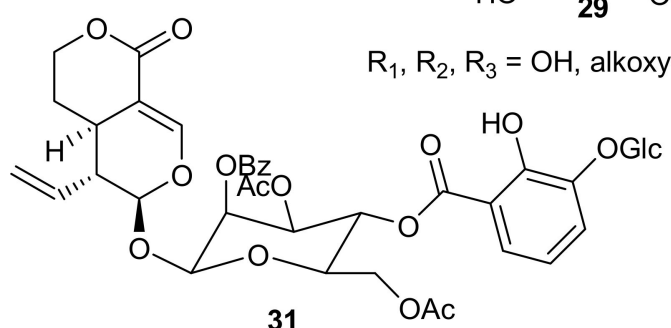
31<smiles>[R]OC(=O)C1=CO[C@@H](O[CH])C(C=C)C1CCC(=O)OCC</smiles>

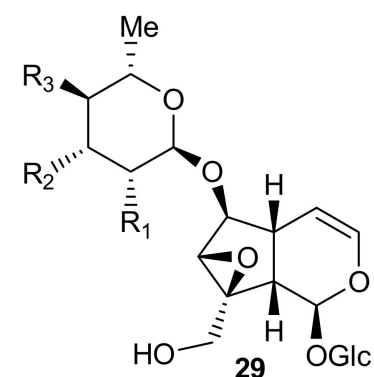

$\mathrm{R}_{1}, \mathrm{R}_{2}, \mathrm{R}_{3}=\mathrm{OH}$, alkoxy group

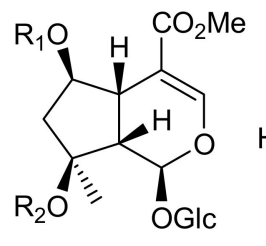

32: $R_{1}=R_{2}=A C$ 33: $\mathrm{R}_{1}=\mathrm{OH}, \mathrm{R}_{2}=\mathrm{Ac}$<smiles>C=CC1C(/C=C/CC(=O)O)C(C(C)=O)=CO[C@H]1O</smiles>

Figure 6. Structures of iridoids 28-37.

\section{Iridoid Derivatives as Antidiabetic Agents}

Lonicera japonica Thunb. is employed in traditional Chinese medicine for detoxification and also to treat pharyngitis, erysipelas, diabetes mellitus, dysentery, fever, respiratory tract infections, and rheumatoid arthritis [31-33]. In addition, pharmacological studies have shown that L. japonica possess various biological properties, including antimicrobial, hepatoprotective, anti-inflammatory cytoprotective, antioxidative, and antiviral effects [31-33]. Song et al. [33] have isolated three new iridoid glycosides named loniceranan A-C (35-37) (Figure 6) from L. japonica and have demonstrated that these compounds possess hypoglycemic effects. Furthermore, the authors claimed that compounds 35-37 can be employed to treat various types of diabetes. Cornus officinalis is used to treat diabetic nephropathy and is also claimed to possess anti-hyperglycemic, anti-oxidant, and anti-aging properties [34]. Kang et al. [35] have reported that the C. officinalis iridoid glycoside possesses significant antidiabetic effects. In addition, this compound not only decreases blood sugar levels but also plays a crucial role in the treatment of diabetes complications, without, encouragingly enough, any side effects for multiple targets.

\section{Miscellaneous}

$\mathrm{Wu}$ [36] has isolated a new iridoid 38 (Figure 7) from Swertia mussotii Franch. In in vitro tests it was demonstrated that this iridoid potently enhances the cell viability of human umbilical vein endothelial cells injured by oxidized low-density lipoprotein (ox-LDL). In addition, Wu has claimed that the iridoid 38 suppresses ox-LDL-induced HUVEC injury, and based on these results, he has suggested that iridoid 38 can be employed in medical preparations for endothelial cell protection. In another patent Yang [37] has reported the isolation of a new iridoid 39 from the bark of Eucommia ulmoides using modern chromatographic techniques. The pharmacological data obtained from an evaluation of this iridoid disclosed that it potently enhances the survival rate of myocardial cells of hydrogen peroxide stress injury. In addition, iridoid 39 significantly reduces the effect of LDH in 
cell cultures. Yin et al. [38] has filed a patent in which the researchers reported that the six iridoid glycosides syringopicroside A (40) and B (41), syringalactone B (42), ligstroside (43), griffithoside B (44), and formoside (45) all possess strong antibacterial effects towards methicillin-sensitive Staphylococcus aureus (MSSA), methicillin-resistant S. aureus (MRSA), and penicillin-resistant S. pneumoniae (PRSP), as well as E. faecalis.

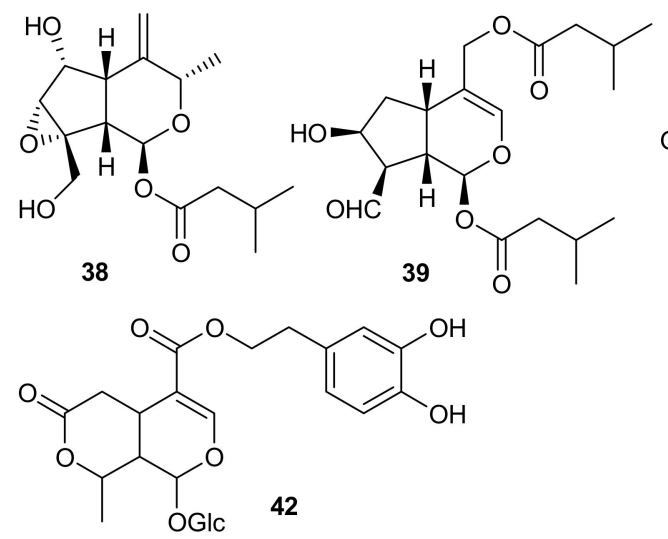

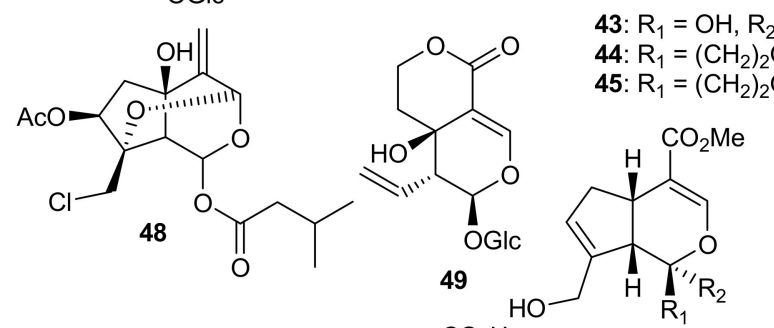

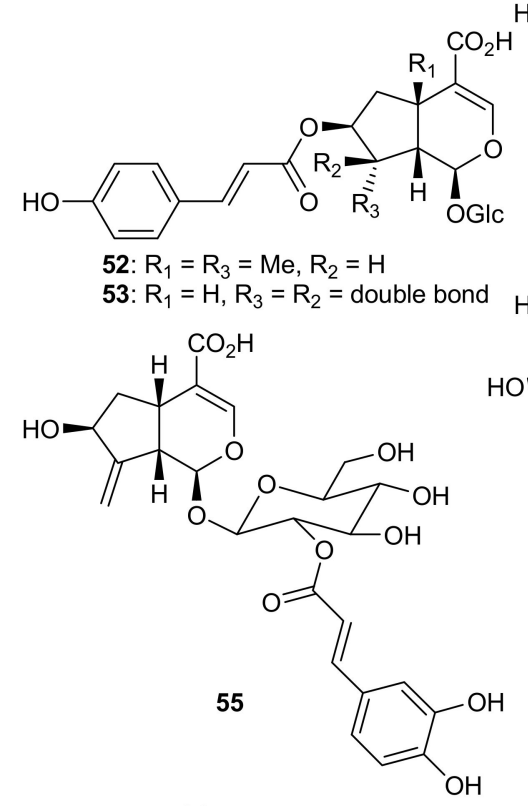

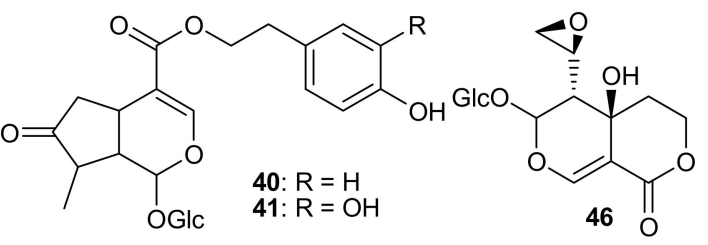<smiles>[R]C([R])=C1C(OC)OC=C(C(C)=O)C1CC(=O)O[Ga]c1ccc([R])cc1</smiles>

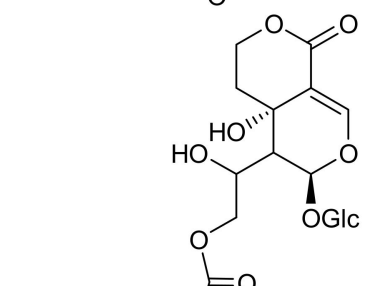


Zhang et al. [40] have also studied the pharmacological action of this compound and have found that it possesses significant effects on TMV without any toxicity. In another patent, Yan et al. [41] described the isolation of iridoid 48 from $\mathrm{V}$. jatamansi and demonstrated that it possesses an encouraging neuroprotective effect. The authors suggested that this compound may be employed to treat CNS disorders, namely Parkinson's disease, Alzheimer's disease, anxiety disorder, and cerebral infarction. Liu et al. [42] have reported that swertiamarin (49), another natural iridoid, can be employed to treat hepatic cirrhosis and hepatic fibrosis. Two further iridoids genipin ether A (50) and B (51), isolated from Gardenia jasminoides Ellis., have been claimed to be used to treat diabetes mellitus, depression, scleroderma, periodontal disease, Parkinson's disease, systemic lupus erythematosus, presenile dementia, asthma, dermatomyositis, and septicemia [43].

The iridoid glycosides 7-O-E-p-coumaroyl-8-epi-loganic acid (52) and 7-O-E-p-coumaroylgardoside (53), isolated from Callicarpa nudiflora, have been evaluated, and based on their pharmacological properties, authors have suggested that these compounds can be incorporated into antithrombotic preparations [44]. On the other hand, genipin-1- $\beta$-gentiobioside (54) has been reported to be used to treat acute influenza, respiratory infection, hepatitis $B$, Epstein Barr virus, pneumonia, Herpes zoster infection, viral myocarditis, simplex keratitis, retroviral and bacterial infection diseases [45]. Other studies have revealed that the iridoid glycosides 55 [46], 56 [47], 57 [48], and 58 [49] (Figure 7) can be employed to treat foot and mouth diseases. Rao et al. [50] have demonstrated that the three natural iridoid glycosides $6-\beta$-hydroxyipolamiide $\left(59: \mathrm{IC}_{50}=138.8 \mu \mathrm{M}\right)$, shanzhiside methyl ester $\left(60: \mathrm{IC}_{50}=104.1 \mu \mathrm{M}\right)$, and 8-O-acetyl shanzhiside methyl ester $\left(61: \mathrm{IC}_{50}=125.0 \mu \mathrm{M}\right)$ display moderate anti-SARS (severe acute respiratory syndromes) properties.

\section{Pharmaceutical Compositions or Formulation Comprising Iridoids}

Colocasia antiquorum has been effectively used to treat swelling, detoxification, erysipelas, sore, blood circulation, chronic bronchitis, bruises, and leptospirosis [51]. Chen [50] has reported that the iridoids contained in the extract of $C$. antiquorum possess significant anticancer effects towards colon cancer (HCT-8 cells) without any toxicity or side effects. In another patent, Bai et al. [52] reported that the seed extract of Fraxinus rhynchophylla contains various iridoid glycosides and may be employed to treat liver injury, although unfortunately these particular iridoids were not identified. In addition, Mascenco et al. [53] have demonstrated that iridoid glycosides present in the extract of Linaria genistifolia show significant antifungal effects towards Fusarium oxysporum. In the same year another patent [54] notes that the rich iridoids contained in extracts of the leaves, stem, and flowers of Japanese honeysuckle can be employed as antipyretic, anti-inflammatory, and antibacterial drugs. Moreover, the Paederia scandens extract, comprising 60-99\% iridoid glycosides, can be used to treat gastrointestinal tract diseases, such as, diarrhea, food retention, and maldigestion [55]. In addition, it has been reported that extracts of $P$. scandens contain iridoid glycosides ( 2 to $25 \%$ of paederoside, 20 to $50 \%$ of paederosidic acid, and 1 to $10 \%$ of methyl paederosidate), which may be used to treat kidney damage [56] and gout [57].

Wang et al. [58] have reported that a gentian pharmaceutical composition containing iridoid glycosides can be employed to treat liver injury. A year later the investigators [59] demonstrated that gardenia sauce vinegar, which contains iridoid glycosides, is capable of controlling heart damage and that this pharmaceutical formulation can improve brain and heart functions. In the same year another researcher reported that glycosylated iridoids present in the extract of the Tabebuia species exhibited inflammatory properties towards snake venom [60]. It has been further disclosed in another patent that the Rhizoma valerianae iridoid-comprising fraction is capable of acting as a calcium channel inhibitor and can additionally be used to treat pain [61]. On the other hand, an Eucommia ulmoides iridoid extract can be employed to treat Alzheimer's disease [62], colon cancer [63], and weight loss effects [64], besides exhibiting cardioprotective properties [65]. One iridoid extract of Forsythia suspensa drink was shown to possess in vitro antibacterial effects in addition to displaying in vivo antibacterial potential in a Staphylococcus aureus-infected model [66]. Extracts of iridoid glycosides from Rehmannia 
glutinosa can significantly decrease blood glucose levels as well as serum creatinine and can increase insulin secretion and urine creatinine. Based on these pharmacological results, it may be concluded that $R$. glutinosa extracts can be used as anti-diabetic and hypoglycemic agents [67].

In a patent by $\mathrm{Li}$ et al. [68] it was reported that Lamiophlomis rotata iridoid glycoside extracts may be used to treat constipation. Extracts of Gentianella acuta comprising 5-15\% of iridoids, namely, decentapicrin, gentiopicrin, and swertiamarin, along with other natural products, can be employed in the treatment of arrhythmia [69]. It has been found that extracts of Cornus officinalis containing iridoid glycosides enhance anti-fatigue ability in mice. Additionally, the authors claimed that the C. officinalis extract has a significant ability to enhance hypoxia tolerance and that this effect was much better than that induced by the standard drugs Ginkgo biloba and nimodipine [70]. Pterocephalus hookeri extracts are employed to treat rheumatoid arthritis, colds, enteritis, and the flu in traditional Chinese herbal medicine. Pharmacological results have demonstrated that the extract of $P$. hookeri possesses in vivo anti-inflammatory and analgesic effects [71]. Zhang et al. [72] have filed a patent in which the group demonstrated that $P$. hookeri iridoid glycoside extracts can be employed to treat rheumatoid arthritis. Furthermore, the Borojoa (Alibertia patinoi) extract, which contains iridoid glycosides, possesses significant antioxidant and antimicrobial effects [73]. In addition, Gardenia jasminoides and Verbena officinalis iridoid glycoside extracts can be used to treat ischemic brain injury [74] and cerebral ischemia [75], respectively.

\section{Conclusions and Future Developments}

Iridoids are undoubtedly one of the most important classes of natural products produced by plants. Furthermore, cytotoxic iridoids may be very important in treating various cancers, namely, ovarian, breast, lung, liver, rectum/colon, osteosarcoma, leukemia, gastric cancer cell, and pancreatic cancer. Most patents on iridoids as anticancer agents present only in vitro evaluation, especially on different cancer cell lines, and it is therefore highly recommended by the current authors that future study should focus also on in vivo evaluation of iridoids. In addition, natural iridoids have been employed as anti-trypanosomal, antileishmanial, antiplasmodial, anti-inflammatory, antidiabetic, antibacterial, and anti-SARS agents. Moreover, iridoids or iridoid glycosides are employed to treat Alzheimer's disease, Parkinson's disease, anxiety disorder, cerebral infarction, diabetes mellitus, depression, scleroderma, periodontal disease, systemic lupus erythematosus, presenile dementia, asthma, dermatomyositis, septicemia, and foot and mouth diseases. Pharmaceutical preparations comprising various plant extracts known to contain iridoids or iridoid glycosides can be used to treat colon cancer, liver injury, diarrhea, food retention, maldigestion, kidney damage, gout, pains, Alzheimer's disease, arrhythmia, ischemic brain injury, and cerebral ischemia. Additionally, iridoids or iridoid glycosides contained in other pharmaceutical compositions are employed as antifungal, antipyretic, anti-inflammatory, antibacterial, anti-diabetic, anti-hypoglycemic, anti-fatigue, analgesic, and antioxidant agents.

During the past decade, only natural iridoids and their glycosides isolated from various plant species have been published in patent literature. To the best of our knowledge, no patent has been published describing any new or novel synthesis of iridoids and iridoid glycosides. However, in the non-patent literature, numerous synthetic iridoids or iridoid glycosides possessing potent anticancer effects towards various cancer cells, i.e., human hepatocellular cells (HepG2), breast cancer cells (MCF-7 and MDAMB-231), epidermoid carcinoma (L1210), and murine leukemia (L1210) [5,76] have been described. Therefore, it is highly recommended by the current authors that new libraries of synthetic analogs of active iridoids should be prepared in order to generate further chemical diversity, since this will no doubt also create interesting biological diversity. Such studies will indeed direct the attention of researchers to understand the composition of the entire pharmacophore necessary for enhancing the anticancer, antileishmanial, antiplasmodial, and antidiabetic properties of iridoids. It is clearly evident from the literature that the addition of halogen and heterocyclic groups to various natural products enhances their biological effects. Therefore, halo-iridoids (especially fluoro- or trifluoro-) and new heterocyclic iridoids should be prepared, since it is firmly believed that these analogs will play an 
extremely crucial role in the future development of improving the effective role of iridoids in drug discovery. Moreover, the current authors have observed that in patents published, the majority of iridoids have sugar moieties attached to the C-1 carbon. Therefore, it is also important to prepare new glycoside analogs of iridoids with one and two sugar units, since this feature will potentially enhance their biological and pharmacological activities, as well as vastly improve on the water solubility of iridoids and thus their in vivo delivery. However, analysis of all published results also demonstrates that increased acylation/etherification results in increased activity generally. Structural diversity, however, may be the best solution to this question. Therefore, another important suggestion is that iridoid dimers, namely homo dimers or heterodimers, should be prepared using amide, ester, or triazole linkages between the monomeric units, since these might quite conceivably possess an increased bioactivity. Moreover, no patent has been published in the last decade on combination therapy (CT), which comprises the mixing of selected iridoids with selected drugs. Therefore, it also highly recommended that hybrid compounds of iridoids should be prepared with other known anticancer, antimalarial and antidiabetic drugs. In addition, future patents should focus on structure activity relationship (SAR) discussions, since these are very rarely presented in the patents under review. Additionally, in vivo studies were not reported for most of the iridoids and the lack of this vital biological data makes a full judgement of their real importance rather difficult. In conclusion, the authors of the current review believe that the future "next generation" of iridoids will include new synthetic analogs of active molecules and novel biological evaluation assays, along with evaluation of toxicity and SAR discussions dealing with all new active iridoids, both synthesized and isolated.

Acknowledgments: The author (H.H.) thanks the Alexander von Humboldt Foundation for its generous support in providing him with the opportunity to work in Germany, which facilitated the writing of this review.

Conflicts of Interest: The authors declare no conflict of interest.

\section{References}

1. Sampaio-Santos, M.I.; Kaplan, M.A.C. Biosynthesis significance of iridoids in chemosystematics. J. Braz. Chem. Soc. 2010, 12, 144-153. [CrossRef]

2. Franzyk, H. Synthetic aspects of iridoid chemistry. Fortschr. Chem. Org. Naturst. 2000, 79, 1-114.

3. Halpern, O.; Schmid, H. Zur Kenntnis des Plumierids. 2. Mitteilung. Helv. Chim. Acta 1958, 41, 1109-1154. [CrossRef]

4. Grignon-Dubois, M.; Rezzonico, B.; Usubillaga, A.; Vojas, L.B. Isolation of plumieride from Plumeria inodora. Chem. Nat. Comp. 2005, 41, 730-731. [CrossRef]

5. Pandeti, S.; Sharma, K.; Bathula, S.R.; Tadigoppula, N. Synthesis of novel anticancer iridoid derivatives and their cell cycle arrest and caspase dependent apoptosis. Phytomedicine 2014, 15, 333-339. [CrossRef]

6. Jensen, S.R.; Nielsen, B.J.; Dahlgren, R. Iridoid compounds, their occurrence and systematic importance in the angiosperms. Bot. Not. 1975, 128, 148-180.

7. Tundis, R.; Loizzo, M.R.; Menichini, F.; Statti, G.A. Menichini F Biological and Pharmacological activities of iridoids: Recent developments. Mini Rev. Med. Chem. 2008, 8, 399-420. [CrossRef]

8. Ghisalberti, E.L. Biological and pharmacological activity of naturally occurring iridoids and secoiridoids. Phytomedicine 1998, 5, 147-163. [CrossRef]

9. Wu, J. New Iridoid, Its Preparation Method and Medical Application Thereof. CN105503892A, 20 April 2016.

10. Yao, T. A Kind of New Iridoid and Its Preparation Method and Medicinal Use. CN105367536A, 2 March 2016.

11. Yang, B.; Zhao, H.; Gu, M.; Song, H. Preparation of Iridoid Ester Compounds for Treatment of Cancer. CN104387362A, 4 March 2015.

12. Thusoo, S.; Gupta, S.; Sudan, R.; Kour, J.; Bhagat, S.; Hussain, R.; Bhagat, M. Antioxidant activity of essential oil and extracts of Valeriana jatamansi roots. BioMed. Res. Int. 2014, 2014. [CrossRef]

13. Yan, Z.; Chen, C.; Lin, Y.; Lan, M.; Zhang, R.; Xu, K.; Zhang, T. Iridoid Compound, and Preparation Method and Use Thereof as Antitumor Agent. CN104086520A, 8 October 2014.

14. Yang, B.; Gu, M.; Cheng, R.; Wang, W.; Chen, J.; Zhang, R. Method for Preparing Epoxy Iridoid Ester Extract of Valeriana jatamansii. CN103599144A, 26 February 2014. 
15. Meng, D.; Zhang, L.; Chen, C.; Xu, L. Preparation Method of Iridoid in Jasminum lanceolarium and Its Application. CN102942605A, 27 February 2013.

16. Zhang, W.; Su, J.; Lin, S.; Shan, L.; Liu, R.; Li, H.; Xu, X. Application of Iridoid Compounds in Preparation of Medicine for Treating Ovarian Cancer. CN101829080A, 15 September 2010.

17. Zhang, W.; Lin, S.; Shan, L.; Su, J.; Liu, R.; Li, H.; Shen, Y.; Xu, X. Iridoid Compounds Extracted from Valeriana officinalis and Its Application as Antitumor Agents. CN101444501A, 3 June 2009.

18. Khanuja, S.P.S.; Srivastava, S.K.; Garg, A.; Khan, M.; Darokar, M.P.; Pal, A. Isolation of Loganin Analogs from Fruit Pulp of Strychnos nux-vomica and Method for their Preparation as Antitumor Agents. WO2007060686A1, 31 May 2007.

19. Jones, A.J.; Grkovic, T.; Sykes, M.L.; Vicky, M.; Avery, V.M. Trypanocidal Activity of Marine Natural Products. Mar. Drugs 2013, 11, 4058-4082. [CrossRef] [PubMed]

20. Yamaoka, S.; Ohta, N.; Suzuki, M.; Shoyama, Y.; Morinaga, O.; Uto, T.; Tung, N.H.; Koram, K.A.; Bosompem, K.M.; Nyarko, A.K. Novel Tetracyclic Spirolactone Iridoid Compounds for Treatment of Trypanosomiasis. WO2015105198A1, 16 July 2015.

21. Hussain, H.; Al-Harrasi, A.; Al-Rawahi, A.; Green, I.R.; Gibbons, S. Fruitful decade for antileishmanial compounds from 2002 to late 2011. Chem. Rev. 2014, 114, 10369-10428. [CrossRef]

22. Buskes, M.J.; Harvey, K.L.; Prinz, B.; Crabb, B.S.; Gilson, P.R.; Wilson, D.J.D.; Abbott, B.M.A. Exploration of 3-methylisoquinoline-4-carbonitriles as protein kinase A inhibitors of Plasmodium falciparum. Bioorg. Med. Chem. 2016, 24, 2389-2396. [CrossRef] [PubMed]

23. Pabbisetty, D.; Illendula, A.; Muraleedharan, K.M.; Chittiboyina, A.G.; Williamson, J.S.; Avery, M.A.; Avery, B.A. Determination of antimalarial compound, ARB-89 (7-hydroxy-artemisinin carbamate) in rat serum by UPLC/MS/MS and its application in pharmacokinetics. J. Chromat. B 2012, 889-890, 123-129. [CrossRef] [PubMed]

24. Urbán, P.; Ranucci, E.; Busquets, X.F. Polyamidoamine nanoparticles as nanocarriers for the drug delivery to malaria parasite stages in the mosquito vector. Nanomedicine 2015, 10, 3401-3414. [CrossRef]

25. Manohar, S.; Khan, S.I.; Rawat, D.S. Synthesis, antimalarial activity and cytotoxicity of 4-aminoquinoline-triazine conjugates. Bioorg. Med. Chem. Lett. 2010, 20, 322-325. [CrossRef] [PubMed]

26. Liu, Z.; Zheng, X.; Wang, L.; Wang, Q.; Chen, H.; Jiang, Y. Preparation Method of 7-O-ethyl-morroniside. CN105968150A, 28 September 2016.

27. Li, Y.; Xu, J.; Zhang, L.; Zhu, T.; Yuan, P.; Chen, X. Pharmaceutical Application of Iridoid Glycoside Compounds. CN105326850A, 17 February 2016.

28. Cheng, Y.; Wang, S.; Wang, Y. Iridoid Compound with Anti-Inflammatory Activity, Its Preparation Method and Application in Preparing Antiinflammatory Medicine. CN103113432A, 22 May 2013.

29. Karan, M.; Kaur, I.; Chopra, D. Anti-Inflammatory Activity of the Iridoid Glycosides. WO2010032269A2, 25 March 2010.

30. Gambhire, M.N.; Wankhede, S.S.; Juvekar, A.R. Antiinflammatory activity of aqueous extract of Barleria cristata leaves. J. Young Pharm. 2009, 1, 220-224.

31. Kwak, W.J.; Han, C.K.; Chang, H.W.; Kim, H.P.; Kang, S.S.; Son, K.H. Loniceroside C, an antiinflammatory saponin from Lonicera japonica. Chem. Pharm. Bull. 2003, 51, 333-335. [CrossRef]

32. Rahman, A.; Kang, S.C. In vitro control of food-borne and food spoilage bacteria by essential oil and ethanol extracts of Lonicera japonica Thunb. Food Chem. 2009, 16, 670-675. [CrossRef]

33. Song, S.; Peng, Y.; Liu, Z.; Li, L.; Liu, Q.; Huang, X. Iridoid Glycoside Compounds in Lonicera japonica and Its Preparation Method and Application. CN105017353A, 4 November 2015.

34. Ma, W.; Wang, K.J.; Cheng, C.S.; Yan, G.Q.; Lu, W.L.; Ge, J.F.; Cheng, Y.X.; Li, N. Bioactive compounds from Cornus officinalis fruits and their effects on diabetic nephropathy. J. Ethnopharmacol. 2014, 153, 840-845. [CrossRef]

35. Kang, J.; Yang, N.; Wang, H.; Bai, Y.; Wang, S.; Wang, Z. Application of Cornus officinalis Iridoid Glycoside in Antidiabetic Agent. CN104784195A, 22 July 2015.

36. Wu, J. Preparation of Iridoid Compound with Endothelial Cell Protection Effect. CN105503893A, 20 April 2016.

37. Yang, H. Extraction of Iridoid Compound from Eucommia ulmoides for Myocardial Protection. CN105481820A, 13 April 2016. 
38. Yin, J.; Zhou, Z.; Han, N.; Liu, Z. New Application of Iridoids and Its Metabolites in the Preparation of Drug-Resistant Bacterial Infection Medicine. CN105687221A, 22 June 2016.

39. Li, G.; Chen, Y.; Zhang, Z.; Dong, J.; Zuo, M.; Zeng, L.; Zhang, J.; Wu, K. An Iridoid Compound and Its Manufacture Method, Preparations and Application. CN105017354A, 4 November 2015.

40. Zhang, Z.; Chen, Y.; Li, G.; Dong, J.; Zhang, J.; Wu, K.; Zuo, M.; Zeng, L. Iridoid Compound (Septemfidoside), and Its Preparation Method, Application in Preparing Drugs for Preventing and Treating TMV (Tobacco Mosaic Virus) and Pesticide Formulation. CN104910224A, 16 September 2015.

41. Yan, Z.; Zuo, C.; Lin, Y.; Lan, M.; Li, S.; Chen, C.; Chen, C.; Zhang, R.; Zhang, T. Iridoid-Like New Compounds, Their Manufacture Method, Neuroprotective Effect and Application. CN103145724A, 12 June 2013.

42. Liu, C.; Yang, T.; Wang, Q.; Tao, Y.; Liu, P.; Shen, L.; Li, S.; Peng, Y. Use of Iridoids and Iridoid Derivatives for Treating Hepatic Fibrosis and Hepatic Cirrhosis. CN103040854A, 17 April 2013.

43. Liu, K.; Zou, X.; Xu, H.; Lang, Y.; Fan, H. Method for Preparation of Iridoid Genipin Methyl ether and Its Medical Application. CN102875518A, 16 January 2013.

44. Luo, Y.; Ma, S.; Fu, H.; Fu, J.; Chen, W.; Huang, B.; Wang, S. Two Iridoid Glycoside Compounds and Production Method and Applications Thereof. CN104892698A, 9 September 2015.

45. Fan, X.; Chen, M. A Novel Pharmaceutical Application of Iridoid Glycoside. CN104510747A, 15 April 2015.

46. Xiao, W.; Yao, X.; Li, H.; Yu, Y.; Wang, Z.; Yao, Z.; Dai, Y.; Gao, H. Iridoid Glycoside Compound and Its Preparation Method and Application. CN104098632A, 15 October 2014.

47. Xiao, W.; Yao, X.; Li, H.; Yu, Y.; Wang, Z.; Yao, Z.; Dai, Y.; Gao, H. Iridoid Glycoside Compound and Its Preparation Method and Application. CN104098630A, 15 October 2014.

48. Xiao, W.; Yao, X.; Li, H.; Yu, Y.; Wang, Z.; Yao, Z.; Dai, Y.; Gao, H. Iridoid Glycoside Dimer Compound, Its Preparation Method and Application. CN104072551A, 1 October 2014.

49. Xiao, W.; Yao, X.; Li, H.; Yu, Y.; Wang, Z.; Yao, Z.; Dai, Y.; Gao, H. Iridoid Glycoside Compound, Its Preparation Method and Application. CN103254259A, 21 August 2013.

50. Rao, Z.; Lou, Z.; Guo, Y.; Chen, W.; Wang, B.; Niu, G.; Feng, J.; Li, J. Application of Iridoid Compounds in Preparation of Anti-SARS Medicament. CN103120699A, 29 May 2013.

51. Chen, G. Preparation Method of Anticancer Iridoid Glycoside Extract of Colocasia antiquorum. CN105878622A, 24 August 2016.

52. Bai, N.; Guo, S.; Liu, Q.; Zhang, Y.; Zhang, L.; Bai, L.; Zhang, X.; Tian, X. Fraxinus rhynchophylla Seed Chemical Composition Standardized Extract and Its Preparation Method and Application. CN105748496A, 13 July 2016.

53. Mascenco, N.; Lupascu, G.; Gurev, A.; Barba, A.; Gorincioi, E.; Gavzer, S. Process for Treating Winter Wheat Against Fusarium oxysporum. MD819Y20141031, 31 October 2014.

54. Liu, S.; Liu, Y.; Zhang, T.; Ji, R. Extract of Japanese Honeysuckle Stem or Flower or Leaf of Its Original Plants Lonicera and Its Preparation Method and Application. CN105311085A, 10 February 2016.

55. Yang, X.; Zhu, S.; Wang, Y.; Dong, Z.; Hou, J.; Cheng, X.; Jiao, X.; Wang, Y.; Jiang, H.; Zhen, P. Paederia scandens Extract, Its Preparation Method and Application. CN105287790A, 3 February 2016.

56. Wu, T.; Shen, X.; Shen, L.; Zhou, H.; Li, M.; Yue, X.; Zhang, Y.; Yan, R.; Zhang, X.; Zhang, M. Paederia scandens Extract and Its Application. CN104398619A, 11 March 2015.

57. Wu, T.; Shen, X.; Li, Y.; Shen, L.; Wang, X.; Zhou, H.; Miao, L.; Zhang, L.; An, Y.; Yin, B. Paederia scandens Water Extract, Its Preparation and Application. CN102846784A, 2 January 2013.

58. Wang, J.; Qin, J.; Zhang, Q.; Chen, G.; Shi, W. Application of Gentian Total Iridoid Glycosides in the Manufacture of a Medicament for the Treatment of Liver Injury. CN105878362A, 28 April 2016.

59. Wang, Z.; Zhang, Y.; Pan, Y. Gardenia Emulsified Vinegar oil and Gardenia Sauce Vinegar and Their Production Method. CN104886546A, 9 September 2015.

60. Carollo, C.A.; Vercosa, D.; Marques, M.R.; Kadri, M.C.T. Tabebuia-Derived Extracts Enriched in Glycosylated Iridoids for Anti-Inflammatory Use. BR2011000685A2, 21 July 2015.

61. Hu, J.; Yang, J.; Nian, Y.; Dong, F.; Jiang, H.; Zhou, J.; Yang, L. Application of Rhizoma Valerianae Latifoliae Iridoid Fraction in Preparing n-Type Calcium Channel Inhibitor. CN104721180A, 24 June 2015.

62. Xiao, J.; Wu, Y.; Zhou, C.; Kang, X.; Chen, L. Pharmaceutical Composition Containing Eucommia ulmoides Iridoid and Application Thereof. CN104523849A, 22 April 2015.

63. Xiao, J.; Wu, Y.; Yang, W.; Chen, J.; Li, X. Eucommia ulmoides Targeted Formulation for Treating Colon Cancer and Its Preparation Method. CN104434950A, 25 March 2015. 
64. Xiao, J.; Wu, Y.; Yang, W.; Chen, L.; Kang, X. Eucommia ulmoides Bark Composition Having Weight Loss Effect and Its Preparation. CN104435068A, 25 March 2015.

65. Xiao, J.; Wu, Y.; Chen, L.; Kang, X.; Mao, J. One Kind of Eucommia Component Composition Having Cardioprotective Effect and Its Preparations. CN104435067A, 25 March 2015.

66. Shi, R.; Wang, Y.; Mei, Y. Drug Having Antibacterial and Synergistic Antimicrobial Activity and Preparation and Application of the Same. CN104306492A, 28 January 2015.

67. Xu, H.; Di, L.; Li, W.; Li, W.; Zhao, T.; Wang, H.; Lv, G. Drug Effective Component Compatible Composition for Preventing and Treating Diabetes and Its Vascular Disease. CN104173568A, 3 December 2014.

68. Li, M.; Jia, Z.; Wang, J.; Tao, R. Application of Lamiophlomis Rotata Total Iridoid Glycoside Extract in Preparing Medicine for Treating Constipation. CN104127486A, 5 November 2014.

69. Kuang, H.; Wang, Z.; Wang, Q.; Yu, Y.; Yang, B.; Zhai, Y.; Song, P.; Xue, J. A Kind of Gentianella Acuta Extract for the Treatment of Arrhythmia, Preparation Method and Use Thereof. CN103638096A, 19 March 2014.

70. Sun, W.; Liang, J.; Zhu, S.; Yu, J. Method for Extracting Cornus Officinalis Total Glycoside Used for Manufacturing Antihypoxic Drug. CN102614243A, 1 July 2012.

71. Zhang, L.; Hu, J.J.; Lin, J.W.; Fang, W.S.; Du, G.H. Anti-Inflammatory and Analgesic Effects of Ethanol and Aqueous Extracts of Pterocephalus hookeri (C.B. Clarke) Höeck. J. Ethnopharmacol. 2009, 123, 510-514. [CrossRef]

72. Zhang, Y.; Meng, X.; Lai, X.; Gu, R. Total Iridoid Glycoside Extract of Pterocephalus hookeri, and Manufacture Method and Applications Thereof. CN102526141A, 4 July 2012.

73. Liang, G.; Liang, Z.; Jiao, H.; Pan, T.; Lv, W.; Huang, J. Borojoa Active Extract and Its Preparation Method and Application in Antimicrobial Agent and Antioxidant. CN102351927A, 15 February 2012.

74. Yang, M.; Zhang, H.; Wang, J.; Liu, H.; Zhao, C.; Zheng, Q.; Yue, P.; Lu, Q. Pharmaceutical Liposome Comprising Geniposide Oriridoid Glycosides of Gardenia jasminoides and Its Application. CN102309449A, 11 January 2012.

75. Miao, M.; Bai, M.; Miao, Y. Application of Total Saponins of Verbena officinalis in Drug for Preventing and Treating Cerebral Ischemia. CN102309622A, 11 January 2012.

76. Rakotondramasy, V.C.; Mouriès, C.; Cachet, X.; Neghra, A.; El Mourabet, M.; Tillequin, F.; Koch, M.; Deguin, B. A novel series of cytotoxic iridoid glucosides derived from aucubin: Design, synthesis and structureeactivity relationships. Eur. J. Med. Chem. 2010, 45, 2314-2320. [CrossRef] [PubMed]

(C) 2019 by the authors. Licensee MDPI, Basel, Switzerland. This article is an open access article distributed under the terms and conditions of the Creative Commons Attribution (CC BY) license (http://creativecommons.org/licenses/by/4.0/). 